\title{
"O TEMPO ALÉM DA ESCOLA" \\ O PAPEL DO PROFESSOR DE EDUCAÇÃO FÍSICA NO \\ CONTRA TURNO ESCOLAR
}

DOI 105902/0102830812543

Data de submissão: 12/01/2014 Data de aceite: 29/09/2014

\author{
Luccas Gonçalves Lima \\ Bacharel em Educação Física UFPR \\ luccaslima@gmail.com \\ Aline Tschoke \\ Instituto Federal do Paraná \\ aline_tschoke@yahoo.com.br \\ Andréia Juliane Drula \\ Instituto Federal do Paraná \\ deia.drula@gmail.com \\ Simone Rechia \\ Instituto Federal do Paraná \\ simone@ufpr.br
}

RESUMO: Este trabalho tematiza o lazer, o professor de educação física e as possibilidades de atuação no contra turno escolar. Foram pesquisadas duas instituições localizadas em Curitiba, uma pública e uma privada. A partir de uma análise qualitativa, com observações sistemáticas, registradas em diário de campo e elaboração das categorias de análise. Conclui-se que é possível a presença de elementos educacionais dentro das práticas de lazer trabalhadas no contra turno, dentre eles destaca-se: a identificação aluno e professor, o incentivo de discussões com enfoque educacional e crítico, formas de apresentar um conteúdo e as relações com suas vivências.

Palavras-chave: Lazer; Contra turno; Professor de Educação Física. 


\section{Introdução}

À medida em que o lazer apresenta-se difundido na sociedade atual, assume diversos âmbitos e direções que podem ser trabalhadas por profissionais interdisciplinares. Nas relações com o esporte, educação e as políticas públicas, o lazer, além de auxiliar para o fortalecimento político e social dos sujeitos em busca da liberdade, podem contribuir para uma vida de mais qualidade. O objetivo desse estudo é analisar o perfil do professor atuante no contra turno ${ }^{1}$ escolar que elabora suas intervenções através de práticas de lazer, buscando verificar em suas práticas de atuação a presença e identificação do que pode ser considerado um elemento formador no desenvolvimento, tanto educacional como crítico, da sociedade participante e, além disso, identificar possíveis diferenças existentes ou não dessa atuação em instituições públicas e privadas.

Socialmente o lazer está muito presente na vida de cada um, porém fica subjetivo afirmar o entendimento da sociedade quanto aos seus significados. Nessa perspectiva, a medida em que são vinculados projetos sociais e políticas públicas, podemos refletir sobre a existência de um caráter formador no lazer implantado nessas intervenções.

Esta pesquisa foi desenvolvida em uma abordagem qualitativa utilizando-se para tanto os seguintes instrumentos metodológicos²: pesquisa de campo - observações sistemáticas, construção de diário de campo e, posteriormente, categorias de análise.

Em ambos os espaços foram analisadas intervenções de lazer que tinham a prática da capoeira como eixo central. Sendo que, no espaço público, a capoeira foi escolhida pelos alunos quando perguntados sobre sua preferência quanto às práticas que seriam trabalhadas. No espaço privado, a capoeira faz parte do quadro de atividades propostas pela instituição.

Após a coleta de dados os mesmo foram sistematizados em categorias de análise as quais serão discutidas a seguir.

\footnotetext{
${ }^{1}$ Contra turno é o período contrário ao horário formal de aula, ou seja, se os alunos freqüentam a aula pela manhã, o contra turno é à tarde e vice-versa (TSCHOKE et al, 2011, p.5).

${ }^{2}$ Para este estudo foi realizada uma pesquisa de campo, composta por 6 observações sistemáticas de intervenções no contra turno escolar de crianças de 6 a 12 anos. Sendo 4 visitas em um centro pastoral, em que consiste o contra turno de uma escola pública no bairro Uberaba, e 2 visitas em espaço de contra turno de uma escola privada, ambas na cidade de Curitiba - Paraná. Tais observações, atividades e diálogos entre professor e alunos ocorridos durante as intervenções foram registradas em diários de campo. Os diários de campo foram elaborados manualmente durante as visitas nos locais escolhidos, através da observação no local da aula sem a intervenção ou participação na atividade que foi observada.
} 
No desenvolvimento desse estudo contamos com a colaboração dos espaços escolhidos para observações, pois houve facilidade no contato com ambos e liberdade para realizar as observações e diários de campo, apenas com uma maior rigorosidade quanto a horários de visita e citação de nome referente à instituição privada.

Além disso, os profissionais envolvidos no estudo se puseram inteiramente a disposição, fornecendo todas as informações necessárias quanto às intervenções, o espaço, planejamento, objetivos, sua formação e quaisquer dúvidas decorrentes das suas práticas.

\section{Entendimentos Necessários}

Antes que possamos nos perguntar sobre a presença de um caráter formador nas práticas de lazer abordadas no contra turno, devemos ter em mente quais as concepções com que estaremos trabalhando, ou seja, devemos primeiramente entender o que tomaremos como Lazer e Contra turno, assim como seus espaços de prática e o professor atuante nessas áreas.

\section{Lazer e tempo livre}

Para chegar a uma definição do tema "Lazer", é necessário analisarmos também os fatores que influenciam na sua existência na atualidade e sua diferenciação para cada indivíduo.

Primeiramente partimos de um dos principais fatores já definido e citado como essencial por diversos autores ao buscar uma definição para o lazer, o "tempo livre". Para Padilha (2004), o tempo livre da sociedade é determinado pelos tempos sociais, e principalmente atrelado ao tempo de trabalho. Quando este não está sendo executado, o sujeito tem um tempo de não trabalho, porém não pode ser feita uma relação direta de tempo de não trabalho com tempo disponível para o lazer, pois dependerá do uso desse tempo, como dialoga a autora

Grande parte dos autores que estudam lazer atribui ao tempo livre a ideia de um tempo em que não se faz nada por obrigação; é, então, um tempo liberto das obrigações no qual se pode optar por fazer alguma atividade prazerosa, descansar ou simplesmente não fazer nada. (PADILHA, 2006, p. 220) 
Sobre o que se faz nesse tempo e o que seria lazer, estaria ligado ao fato do lazer ser uma esfera desse tempo livre, sendo necessárias outras interpretações e conceituações do fenômeno lazer para um maior entendimento.

Assim, os principais conceitos referentes ao lazer são fundamentados nas concepções do sociólogo francês Joffre Dumazedier

O lazer um conjunto de ocupações às quais o indivíduo pode entregar-se de livre vontade, seja para repousar, seja para divertir-se, recrear-se e entreter-se, ou ainda, para desenvolver sua informação ou formação desinteressada, sua participação social voluntária ou sua livre capacidade criadora após livrar-se ou desembaraçar-se das obrigações profissionais, familiares e sociais (2001, p.34).

A definição de Dumazedier se tornou por muitos anos a principal fonte para estudos sobre o lazer, porém atualmente percebemos a necessidade de ressaltar a influência que o Estado exerce na definição das políticas públicas e na constituição de espaços públicos para a prática social do lazer. Além disso, o tempo livre também é negligenciado, de certa forma, por Dumazedier ao definir o lazer, e este seria crucial por ser encarado por Oleias (2003), como uma conquista de classe que terá reflexo direto no direito e exercício do lazer da sociedade.

Tal conquista do tempo livre em oposição à jornada de trabalho aparece no conceito de Camargo (1986), que o define como qualquer atividade que não seja profissional ou doméstica, com caráter gratuito e prazeroso somado também ao papel educacional do lazer perante a sociedade.

Nesse conceito, que pode ser considerado próximo ao de Dumazedier, Camargo (1986) traz, além da conquista do tempo livre sobre o trabalho profissional, a oposição ao trabalho doméstico para a vivência do lazer, o que se faz importante nas dimensões de entendimento do tempo livre, sendo um tempo totalmente disponível à vivência do ócio ou qualquer atividade que seja de espontânea escolha do indivíduo.

À medida que é apresentado o lazer como um potencial agente de desenvolvimento crítico, criativo e transformador do indivíduo, coloca-se em pauta o direito de todos ao lazer e o dever do Estado em proporcionar condições para tais vivências. Nesse sentido, destaca-se que o lazer deve ser entendido como direito social presente no artigo $6^{\circ}$ da Constituição Federativa Brasileira. 
Para Marcellino (2006), o entendimento do lazer de forma isolada, sem considerar as influências de outra esfera social, pode provocar uma série de equívocos, como sua utilização apenas como consumo, fonte de alienação ou fuga. Assim, o lazer seria promovido como:

Finalidade da existência e ideal de felicidade. Dessa forma, todos os problemas pessoais e sociais estariam resolvidos, num passe de mágica, ou pelo menos, 'compensados', pelas possibilidades oferecidas pelo lazer. (MARCELLINO, 2006, p.15)

O mesmo autor defende ainda que o lazer deva ser considerado como um tempo privilegiado para a vivência de valores que contribuam para mudanças de ordem moral e cultural, não devendo ser entendido como simples assimilador de tensões e injustiças sociais.

Para Marcellino, (2006, p.16) a realização de uma atividade de lazer envolve "a satisfação de aspirações dos seus praticantes", essa satisfação varia de pessoa para pessoa, e a escolha deve ser feita com autonomia, seja em um ou mais interesse que o indivíduo optar ${ }^{3}$.

No entanto, para o autor o que ocorre geralmente é a pessoa praticar unicamente um grupo de interesses sempre que obtém seu tempo livre, e isso acontece não por opção do indivíduo, mas porque, talvez, não tenha tomado conhecimento dos outros diversos conteúdos e assim diminuindo suas possibilidades e sensibilidades de aproveitamento do tempo livre para desenvolvimento de suas relações tanto sociais, manuais ou de qualquer outro conteúdo do lazer.

É possível observar que os autores apresentam alguns pontos diferentes em suas definições do lazer, ora trazendo mais elementos influentes para o lazer ou defendendo o lazer como simplesmente de responsabilidade apenas do indivíduo. Porém, as definições se assemelham ao apresentar o lazer sempre como sendo a prática de alguma atividade de livre escolha, critério ou modo de utilização do indivíduo, ou até mesmo a liberdade de optar pelo ócio em seu tempo livre, ou seja, de distância do trabalho ou de qualquer atividade que seja imposta ou necessária.

Assim, podemos assumir que, apesar das divergências dos autores em sentidos pontuais e em contínuo desenvolvimento acompanhante da linha do tempo, há uma proximidade

${ }^{3} \mathrm{O}$ autor apresenta esses conteúdos classificados em seis áreas fundamentais: os interesses artísticos ("emoções e sentimentos"), os intelectuais ("busca de informação e racionalidade"), os físicos ("movimentos corporais e exercícios físicos"), os manuais ("manipulação de objetos"), os turísticos ("novos ambientes") e os sociais ("relações e interações"). A partir dessas definições dos conteúdos apresentados para entendimento das possibilidades das práticas do lazer, Marcellino (2006) defende a interação entre todos esses interesses classificados, gerando uma possibilidade da vivência do lazer completa para o indivíduo. 
entre os argumentos que assumem o lazer como dependente do "desenvolvimento pessoal do indivíduo" e seu tempo livre. Assim, o exercício do direito ao lazer surge na liberdade e possibilidade de escolha do homem em relação às atividades realizadas, ou até mesmo a ausência delas, que irá preencher seu tempo disponível, de forma que lhe traga prazer e satisfação.

$\mathrm{Na}$ infância o tempo de lazer das crianças muitas vezes aparece em contraponto com a grade horária da escola. Porém, a implementação de atividades no contra turno escolar podem aparecer como possibilidade de vivência do lazer para essa faixa etária.

\section{Contra turno escolar}

As crianças brasileiras não passam, em média, mais de quatro horas por dia nas unidades de Ensino Fundamental, segundo um levantamento da Fundação Getúlio Vargas (FGV) divulgado em abril. A Lei de Diretrizes e Bases da Educação Nacional (LDB) pede a ampliação desse tempo, somado a isso, Krolow e Castelleins (2009, p.3859) definem escola em tempo integral como:

[...] alternativa da aprendizagem que visa à complementação das oportunidades de aprendizagem, oferta de atividades educativas diversas, articuladas dentro do espaço escolar quanto dos demais espaços públicos, caracterizando um turno complementar para o ensino fundamental.

Com luz a essas possibilidades de entendimento, experiências para estender o período começam a aparecer no país sendo utilizadas no contra turno escolar, período extra, fora da grade horária das matérias regulares, em que as crianças realizam atividades propostas pela diretoria de cada instituição. São projetos que integram atividades ao turno escolar para aumentar a carga horária dos estudantes, que pode alcançar até oito horas, promovida pelo governo, ONG's, ações sociais ou reforço escolar.

No Brasil há muito tempo já pode ser identificada a discussão em relação ao contra turno e a implementação da chamada Educação Integral, segundo a Secretaria de Educação Continuada, Alfabetização e Diversidade do Ministério da Educação (Secad/MEC) (2009)

Desde a primeira metade do século $X X$ encontramos investidas significativas a favor da Educação Integral, tanto no pensamento quanto nas ações de cunho educativo de católicos, de anarquistas, de integralistas e de educadores como Anísio Teixeira, que tanto defendiam quanto procuravam implantar instituições escolares em que essa concepção fosse vivenciada (Secad/MEC, 2009, p.16). 
Segundo a Secad/MEC (2009) em seu texto que serviu de referência para o debate nacional, Anísio Teixeira, um dos mentores intelectuais do Manifesto dos Pioneiros da Escola Nova, pensando na implementação de um Sistema Público de Ensino para o país, propunha uma educação em que a escola proporcionasse às crianças um programa completo de leitura, aritmética e escrita, ciências físicas e sociais, e mais artes industriais, desenho, música, dança e educação física, saúde e alimento à criança, visto não ser possível educála no grau de desnutrição e abandono em que vivia. Segundo o artigo em questão, Anísio Teixeira colocou em prática essa concepção no Centro Educacional Carneiro Ribeiro, em Salvador, na Bahia, na década de 1950. Ainda segundo o autor, nesse Centro, poderiam ser encontradas atividades, historicamente entendidas como escolares, sendo trabalhadas nas Escolas-Classe, bem como outra série de atividades acontecendo no contra turno escolar, no espaço que o educador denominou de Escola-Parque.

Atualmente, autores e estudiosos da área da educação e psicopedagogia abordam o contra turno escolar, suas possibilidades e benefícios que podem ser encontrados em suas intervenções. Krolow e Castelleins (2009, p.2) apresentam em seu estudo o contra turno visto como "um espaço de desafio para a educação do futuro no Ensino Fundamental".

Para os autores, um dos graves problemas da educação é o pequeno tempo escolar, aliado aos escassos espaços e recursos oferecidos aos alunos.

A melhoria dessas situações propiciaria o diálogo e conseqüentemente a aprendizagem dos alunos despertando maior interesse em freqüentar as aulas proporcionando uma escola integrada, com espaço de permanência e que favoreça qualidade do ensino dentro da mesma. (KROLOW e CASTELLEINS, 2009. p.2)

Assim, entende-se o contra turno como uma importante ferramenta no processo de desenvolvimento do aluno, mas para isso se faz necessário o aprimoramento de espaço e tempo, capazes de proporcionar aos alunos práticas de qualidade e que despertem o interesse nas atividades em seu tempo extraclasse.

Portanto, entende-se que juntamente com a implementação de atividades no contra turno escolar faz-se também importante tratar dos espaços em que serão desenvolvidas essas atividades, o entendimento de suas possibilidades e também adversidades que permeiam as intervenções, assim como o perfil do professor atuante no contra turno que tem papel importante no desenvolvimento do indivíduo através de tais intervenções citadas. 


\section{Espaços de contra turno e professor de educação física}

Assim como apresentado anteriormente, o contra turno aparece definido pelos autores que dedicam seus estudos sobre o tema, como uma possibilidade importante para a ampliação do tempo em que o aluno permanece na escola e também com a capacidade de contribuir no desenvolvimento mais amplo do aluno.

A implementação da escola integral pode despertar maior interesse na criança em frequentar as aulas, descobrindo que além da educação ou formação intelectual, poderá ter uma vida mais saudável interagindo com outros alunos, somando valores, aumentando seu rendimento físico, intelectual e social, com isso despertando a vontade de estar envolvido ativamente na prática educativa. (KROLOW; CASTELLEINS, 2009. p.3)

Porém, além dos possíveis benefícios sobre o contra turno e escola integral, também entra em discussão a importância de um espaço e recursos de qualidade que possam oferecer um ensino de qualidade e vivências significativas para os alunos. E, além disso, afirma-se a importância do professor coerente com esta proposta diferenciada, afinal não deve ser somente uma ampliação do período de estudo, mas sim um novo tempo de possibilidades de vivenciar outros aspectos da educação além dos conteúdos formais.

O desafio é criar espaços que favoreçam novas relações no interior da instituição escolar para que alunos, pais, funcionários e professores tornem-se um coletivo capaz de construir uma escola onde os saberes estejam voltados para as aprendizagens do aluno e sua formação como cidadão comprometido com a transformação da sociedade. (OLIVEIRA, 1997, p. 146 citado por KROLOW; CASTELLEINS, 2009)

Segundo o mesmo autor, destaca-se que o mesmo espaço escolar deve ser mais atrativo, porém tal processo é repleto de dificuldades no que tange a criação novas concepções no mesmo espaço onde é de costume a visão rotineira e uniforme, aspectos presentes no contra turno, pois normalmente é realizado no mesmo espaço das demais atividades curriculares que carregam tal imagem de rotina, uniformidade e, muitas vezes, formalidade. Essa nova abordagem deve atingir a comunidade em sua totalidade, visto que o objetivo trata-se da formação dos cidadãos que convivem em sociedade e em sua complexidade.

Em seu texto, a Secad/MEC avança ao ponto que apresenta que:

A escola - por meio de planejamento, projetos integrados e também de seu projeto pedagógico - pode proporcionar experiências, fora de seu espaço formal, que estão vinculadas a esses seus projetos institucionais, elaborados pela comunidade escolar. Encontram-se, nesse caso, por exemplo, as visitas a museus, parques 
e idas a outros espaços socioculturais, sempre acompanhadas por profissionais que, intencionalmente, constroem essas possibilidades educativas em outros espaços educativos que se consolidam no projeto maior - o do espaço formal de aprendizagens. (2009, p.36)

Assim, a Secad/MEC assume que qualquer ambiente pode ser educacional, ficando incumbido ao professor o papel de transformar e planejar intervenções e propostas que incitem o aluno a desenvolver críticas e conceitos ao que lhe é apresentado.

Nas palavras de Guará (2009, p.1):

Uma aula-atividade em um ambiente diferente propicia um novo olhar sobre as relações. A discussão quanto a sua preparação, sua avaliação e os conflitos ocorridos não representa prejuízo no desenvolvimento dos conteúdos propostos. Significa, sim, que os conteúdos foram ampliados e não se considera que planejare avaliar são aspectos apenas do aprendizado de qualquer disciplina, como também o são para a vida. E que os conflitos ocorridos não desqualificam a atividade, ao contrário, enriquecem-na, desenvolvendo competências diversas.

A extrema importância do papel do professor é ressaltada em outro trecho do texto referencial da Educação Integral, em que a Secad/MEC aponta que:

O educador é aquele que reinventa a relação com o mundo, que reinventa sua relação com o conteúdo que ensina, com o espaço da sala de aula e com seus alunos. É aquele que se permite ver nos alunos possibilidade e processos em realização. Por isso pode ser comparado a um artista na arte de mediar aprendizagens e buscar sempre o (re)encantamento com sua profissão. (Secad/ MEC, 2009, p.44)

Ao comparar o educador ao artista, dá ao professor o poder e a responsabilidade de ser o principal mediador do interesse do aluno a adentrar e dedicar-se a proposta educacional trabalhada em sua intervenção.

Nesse mesmo enfoque, Arruda e Vieira (2010) dialogam sobre questões acerca da educação integral:

Verificamos que é preciso pensar em atividades que atendam a clientela no contra turno, dentro de um repertório diversificado, com aulas passeio, com o máximo de participação e envolvimento dos alunos, pois o tempo que os mesmos permanecerem na escola deve ser prazeroso, para que se desgaste a relação aluno-escola. Podemos então refletir que o educador que atua dentro do ensino integral, deva redobrar suas pesquisas e criatividade na elaboração de propostas de atividades diferenciadas que valorize o conhecimento prévio do aluno, que o faça sentir-se parte da proposta e principalmente que tenha significado em seu contexto social. (p.1)

Dessa forma, o professor atuante no contra turno tem a responsabilidade de extrapolar os limites da sala de aula e da educação curricular, mesmo que, em algumas ocasiões, 
possa estar dentro da sala. Ele deve ser capaz de identificar a individualidade do seu aluno para criar em sua prática educacional uma relação com o ambiente externo que é vivido pelo aluno em sua particularidade, assim como criar relações com situações cotidianas e assuntos de formação crítica para realmente ter um resultado no desenvolvimento do aluno. Além disso, suas práticas e metodologias devem ser prazerosas e que busquem a quebra da rotina e formalidade que o aluno já enfrenta em seu período dentro da sala de aula com as matérias curriculares, na busca pela diversidade e ludicidade.

Nessa concepção, o professor de educação física pode e deve contribuir em tais fatores, uma vez que já carrega em sua metodologia o caráter mais lúdico em suas práticas e a utilização de um ambiente diferenciado das práticas comuns, em sua maioria.

Portanto, conforme apresentada tal importância das práticas no contra turno escolar, este estudo busca verificar a existência de um elemento considerado educacional na formação do indivíduo através das práticas de lazer escolhidas pelo profissional para serem trabalhadas com as crianças nesse tempo.

\section{Os Espaços Pesquisados}

Os espaços que serviram como objeto de estudo dessa pesquisa foram escolhidos pelo encaixe que apresentaram com a proposta do trabalho, pois ambos abordam práticas de lazer em seu contra turno e apresentam semelhanças, como o conteúdo trabalho e a influência religiosa em seu método de ensino, e diferenças, como a localização, entre si que foram significativas para o interesse do estudo, sendo que em ambos os espaços foram observadas intervenções que trabalharam com a capoeira como lazer em seu contra turno.

O primeiro espaço trata-se de um espaço de contra turno de uma escola municipal em área de vulnerabilidade social de Curitiba, onde as intervenções de contra turno eram ministradas por universitários da graduação em Educação Física ${ }^{4}$.

As outras duas intervenções analisadas nesse primeiro espaço coincidiram com a chegada de um novo profissional naquele ambiente, sendo um aluno do $8^{\circ}$ período ( $4^{\circ}$ ano), passando pela situação de primeiro contato entre professor e alunos.

As duas primeiras intervenções analisadas nesse espaço foram realizadas por uma aluna do $5^{\circ}$ período $\left(3^{\circ}\right.$ ano) do curso de Educação Física da Universidade Federal do Paraná que estava realizando as intervenções há 2 meses e apresentava proximidade com os alunos.

Profissional formada pela Universidade Federal do Paraná, sendo uma professora específica da modalidade trabalhada que atua no colégio já a 5 anos. 
O segundo espaço constitui-se de um contra turno de uma escola privada de Curitiba de grande estrutura física e organizacional. As aulas de contra turno analisadas nesse espaço foram ministradas por uma professora doutora em Educação Física .

Dessa maneira, os espaços selecionados tornam-se válidos e interessantes para o projeto na medida em que ambos têm influência religiosa em sua missão e trabalham com a mesma prática em seu contra turno, porém apresentam diferenças estruturais e dos professores atuantes que favorecem a discussão e análise de elementos que possam demonstrar influência quanto à identificação do problema de pesquisa, o caráter educacional nessas práticas de lazer.

\section{Instituição pública}

O contra turno público escolhido é uma obra mantida por Irmãs Felicianas no Bairro do Uberaba, Jardim Alvorada, em Curitiba, com crianças da comunidade, na faixa etária de 5 a 11 anos, por meio de atividades recreativas, teatros, jogos, músicas, desenhos e pinturas.

Segundo o Serviço de Orientação Religiosa (SOR) do colégio, a atividade voluntária em que consiste o Centro Pastoral tem por objetivo sensibilizar e despertar o jovem e a comunidade educativa para a prática da paz, solidariedade, fraternidade e partilha, através de atos concretos, a exemplo da Bem-Aventurada Maria Ângela, que acolhia com amor os menos favorecidos.

Em seu website, o SOR apresenta o projeto Pastoral Voluntário, que trata-se do Centro Pastoral, como "imbuído do Carisma Feliciano - que nos traz força e vontade para alcançar nossas metas - e tem dado a sua parcela de contribuição na construção de um mundo mais justo, com a participação de jovens que acreditam na união, no bem comum, na doação e têm acima de tudo amor fraterno, seguindo o exemplo de Jesus Mestre e acreditando que o pouco que fazem é uma grande parcela para que a sociedade possa ser melhor".

Para o Serviço de Orientação Religiosa do colégio responsável pelo projeto "aí está o verdadeiro sentido da Pastoral Voluntária do Assunção: despertar para a Solidariedade, Partilha, Fraternidade e Paz, com muito, muito entusiasmo!" 
Instituição privada

A outra instituição pesquisada trata-se de uma escola privada localizada em Curitiba. $\mathrm{O}$ colégio trata-se de uma referência para o ensino da cidade, pela sua estrutura privilegiada e seu método de ensino, e influência jesuíta.

Essa instituição tem sua correlação com essa pesquisa pelo programa que disponibiliza em seu contra turno. Além das modalidades esportivas trabalhadas o colégio tem um programa de cultura e arte, oferecendo aos alunos aulas de teatro, dança, desenho, cinema e a capoeira.

Em seu website, a escola define que sua missão é "buscar a excelência na educação, inspirada na proposta da Companhia de Jesus (jesuítas)". Em que, "cabe à escola propor grandes desafios ao aluno, acompanhando-o com respeito e ajudando-o a formar e se formar como elemento distintivo de nossa proposta para um mundo melhor".

Assim, a escola apresenta em sua missão um desenvolvimento pessoal, religioso e crítico dos seus alunos e para isso aliam a educação curricular com a implementação de atividades culturais na carga horária e contra turno dos alunos.

\section{Elementos a Serem Considerados: Surgem as Categorias de Análise}

A partir dos diários de campo elaborados durante as observações sistemáticas nos espaços selecionados foi possível encontrar elementos a serem considerados das duas intervenções que nos favorecem a identificar subsídios importantes na averiguação da relação do aluno com o professor e com as práticas corporais aplicadas nas intervenções.

\section{Identificação}

A primeira categoria presente nos diários de campo é a identificação dos alunos com o professor, em ambos os espaços, como fica evidente no seguinte trecho:

Os alunos ficaram muito empolgados com a chegada da professora e com a atividade proposta. A professora explicou aos alunos o que seria feito e disse a eles que levaria seus trabalhos para serem expostos no Departamento de Educação Física da Universidade Federal do Paraná. (Diário de Campo, Espaço público, 2011) 
Essa identificação pode ser relacionada com o que é apresentado no texto da Secad/MEC (2009) em que o profissional atuante aparece comparado ao artista com a responsabilidade de ser o principal mediador do interesse do aluno a adentrar e dedicar-se a proposta educacional trabalhada em sua intervenção.

Nesse caso, a professora do espaço público remete além de uma identificação construída com o número de intervenções já realizadas com os alunos, atribui também certa importância ao trabalho que seria realizado pelos alunos, sendo que seriam levados para ser expostos na universidade.

Outras passagens registradas nos diários de campo remetem tal identificação dos alunos com a professora do espaço público, como no seguinte trecho:

"As crianças disputavam pela atenção da professora (...) apenas alguns alunos ficaram na sala para ajudar a mesma a guardar os materiais, os demais corriam pela escola ou iam embora sozinhos". (Diário de Campo, Espaço público, 2011)

Apesar de poucos alunos ficarem para ajudar a professora, tal identificação se dá pela opção dos alunos em ficar, não havendo qualquer cobrança ou pedido da professora para isso.

Na mesma categoria, porém em sentido contrário, alguns trechos demonstram como a falta de identificação dos alunos com o novo professor, talvez por não ter havido tempo para tal desenvolvimento, prejudicou o andamento da proposta elaborada.

(...) Quando o professor pediu para que os alunos levantassem, todos começaram a correr e fazer bagunça pela sala(...) O professor sugeriu uma brincadeira para as crianças mas elas não respeitavam e queriam brincar de outra coisa." (Diário de Campo, Espaço público, 2011)

Pode-se inferir que o professor não conseguiu realizar sua prática planejada em virtude de não alcançar uma conexão com os alunos e assim não houve sucesso em despertar o interesse deles pela prática vivenciada.

\section{Intervenção como forma de formação}

A segunda categoria identificada nos diários de campo foi a intervenção dos professores durante a prática com o papel de educador. Em alguns trechos dos diários ficou explícita a participação do professor do espaço público indo além de aplicar uma atividade apenas 
pela sua prática, mas sim atribuindo um significado a ela promovendo discussões com o sentido de formação do aluno, como segue no primeiro diálogo descrito abaixo.

"Após isso a professora comentou sobre os desenhos violentos e pediu para que refizessem os desenhos.

- Por que esse homem está chutando a cabeça do outro?

- É um assalto professora!

- Mas é isso que vocês aprenderam na capoeira? Não foi isso que eu ensinei. Faz um desenho bonito ai de vocês virando um 'ahu' ou da roda.

- 'tá bom!'” (Diário de Campo, Espaço público, 2011)

Em outro diálogo registrado nos diários a professora do espaço público promove outra discussão que faz menção à violência demonstrada por outro aluno.

"- O que é isso?

- Eles brigaram e ele arrancou a cabeça do outro!

- Nossa, que feio isso. Capoeira não é assim que joga né? Faz um desenho do que a gente brincou na aula passada, você lembra?

- Lembro.

- Então faz para eu ver". (Diário de Campo, Espaço público, 2011)

Ao intervir durante a atividade e promover tais discussões a professora busca uma reflexão dos alunos para com situações que já são consideradas comuns para o dia-a-dia em que estão acostumados, assim como apresentou Guará $(2009$, p.1) defendendo que as atividades do contra turno devem "propiciar um novo olhar sobre as relações".

Tal reflexão para novos olhares aparece em outro trecho já no ambiente privado quando aparece um caráter de competição, muito comum em ambientes escolares, entre os alunos que também tem intervenção da professora.

"Alguns alunos começaram a competir para ver quem fazia melhor os exercícios e com maior grau de dificuldade e por isso os alunos começaram a discutir e a professora disse que "era só treinar que todos conseguiriam fazer'." (Diário de Campo, Espaço privado, 2011)

Nessa intervenção a professora coloca todos em igualdade e remete a importância de perseverança e determinação para êxito. Tal caráter de formação adquirido também estaria presente caso a professora estimulasse o lado da competição, porém estariam sendo abordados outros valores.

Porém, é necessário frisar que as intervenções, consideradas de sucesso com os alunos, foram realizadas pelas professoras que já apresentavam alguma identificação com os alunos, como já exposto anteriormente. 


\section{Conteúdo interessante}

Por fim, outra categoria que se destacou foi o interesse dos alunos pelo conteúdo, sendo a Capoeira em ambos os espaços, trabalhado nas intervenções, como relatam alguns trechos:

“(...)a aula foi bem desenvolvida pois quando chamados os alunos queriam mostrar o domínio do conteúdo aprendido.

(...)O mesmo aluno que estava respondendo continuou dizendo que os portugueses pensavam que era uma luta e por isso proibiram a capoeira e batiam nos escravos sempre que eles estavam dançando e praticando a capoeira." (Diário de Campo, Espaço público, 2011)

Essas passagens remetem um interesse dos alunos pelo conteúdo trabalhado nas intervenções e o sucesso das estratégias adotadas pelos professores, uma vez que despertando o interesse dos alunos pelas práticas a participação e satisfação dos mesmos são maiores favorecendo a identificação dos alunos com o professor e assim a inserção das discussões que irão servir como elemento formador.

Assim como citado anteriormente, esse papel do profissional em gerar tal interesse aparece na conclusão de Arruda e Vieira (2010, p.1) ao dizer que "o educador que atua dentro do ensino integral deve redobrar suas pesquisas e criatividade na elaboração de propostas de atividades diferenciadas que valorizem o conhecimento prévio do aluno", pois para os autores isso deverá fazer o aluno sentir-se parte da proposta e terá significado em seu contexto social.

A partir dessa análise podemos identificar o papel dos professores de educação física analisados nos espaços pesquisados como tendo obtido sucesso, e assim, como nas palavras de Arruda e Vieira (2010), atribuir a eles o adjetivo de educador.

\section{Conclusão}

Com o desenvolvimento dessa pesquisa, após o entendimento dos conceitos básicos do lazer e contra turno, seguido das observações e acompanhamento de intervenções nos espaços escolhidos, e conseqüente análise das categorias, foi possível elaborar conclusões a cerca dos subsídios que permeiam a possibilidade da existência de um elemento que possa ser considerado educacional/formador nas práticas de lazer no contra turno escolar.

Inicialmente e de relevante importância, com a observação das intervenções foi 
concluído que é possível incluir elementos educacionais nas práticas de lazer, porém isso não ocorre de forma inflexível e através de um planejamento rigoroso, são necessárias práticas que exigem ainda mais do professor.

A primeira condição que se mostrou imprescindível para a abertura dos alunos para com a proposta do professor é a identificação entre ambos. Nas intervenções ficou claro que para haver uma conexão e aceitação por parte dos alunos é necessário ser criado um vínculo com o professor, que não ocorre de maneira forçada, mas sim com o decorrer das práticas e através das estratégias do profissional.

Essas estratégias constituem as outras duas condições que se apresentaram importantes para o desenvolvimento de um sentido educacional nas práticas de lazer, sendo a primeira a capacidade do profissional de saber o momento e o modo de intervir em situações aparentemente comuns durante a prática que está sendo realizada, mas que carregam um significado de subjetiva importância para o aluno que pode ser trabalhada.

A segunda é atribuir valor ao conteúdo apresentado e elaborá-lo de forma que gere o interesse dos alunos, assim resultando no envolvimento deles com a prática facilitando a possibilidade de intervenções e discussões que serão construtivas para a formação.

Portanto, mais importante que um espaço de grande estrutura física com disponibilidade de materiais diversos para práticas de lazer, é a consciência do professor sobre o seu papel para com os alunos que estão envolvidos em sua prática, tornando-se assim um educador.

Mostra que ele deve ter em mente os fatores que possibilitarão que sua intervenção torne-se um método educacional para o desenvolvimento pessoal e crítico dos seus alunos. Portanto, essa pesquisa confirma a importância do professor de educação física no contra turno escolar, atuando realmente como um educador através das práticas lúdicas vivenciadas no tempo/espaço de lazer das crianças. 


\section{Referências}

ARRUDA, Maria Rita de Barros; VIEIRA, Vilma de Souza Martins. Pensando nas propostas de atividades no contra turno da escola em tempo integral. Infoeducativa, 2010.

CAMARGO, Luiz Otavio de Lima. O que é lazer? São Paulo, Brasiliense, 1986.

DUMAZEDIER, Joffre. Lazer e cultura popular. 3. ed. São Paulo, Perspectiva, 2001.

GUARÁ, Isa Maria Rosa. Educação Integral: Articulação de projetos e espaço de aprendizagem. Disponível em < http://www.cenpec.org.br/modules/xt_conteudo/index. php?id=46>. Acesso em 25/11/2011.

KROLOW, Aderlei Correa Milech; CASTELEINS, Vera Lucia. Contra turno: Um espaço de desafio para a educação do futuro. In: IX Congresso Nacional de Educação. Anais..., Curitiba, 2009.

MARCELLINO, Nelson Carvalho. Estudos do Lazer: uma introdução. Campinas, SP. 2006.

OLEIAS, Valmir José. Conceito de lazer. 2003. Disponível em: <http://www.cds.ufsc. br/ valmir/cl.html>. Acesso em: 14/10/11.

PADILHA, Valquíria. (Org) Dialética do lazer. São Paulo: Cortez, 2006.

Secad/MEC. Série Mais Educação: Educação Integral. Brasília, 2009. Disponível em:

$<$ http://portal.mec.gov.br/dmdocuments/cadfinal_educ_integral.pdf.>. Acesso em 26/11/2011.

TSCHOKE, Aline; TARDIVO, Thais Gomes; RECHIA, Simone. Como a Escola se Tornou Também Espaço de Lazer da Comunidade: Os Programas Inseridos a Escola Maria Marly Piovezan. Pensar a Prática, Goiânia, v. 14, n. 1, p. 1-11, jan./abr. 2011. 


\section{“IN ADDITION THE TIME SCHOOL": THE TEACHER'S ROLE OF PHYSICAL EDUCATION IN ROUND AGAINST SCHOOL}

ABSTRACT: This work thematizes leisure, physical education teacher and the possibilities of action against the school day. Two institutions located in Curitiba, one public and one private were surveyed. From a qualitative analysis with systematic observations, registered in a diary and preparation of analytical categories. We conclude that the presence of educational elements is possible within the leisure practices worked against in turn, stands out among them: identifying student and teacher, encouraging discussions with educational and critical approach, ways of presenting content and relations with their experiences.

Keywords: Leisure, Contra shift, Professor of Physical Education.

\section{"ALLÁ DEL TIEMPO ESCOLAR"PAPEL DEL PROFESOR DE EDUCACION FISICA EN TURNO EN CONTRA LA ESCUELA}

RESUMEN: Esta obra tematiza ocio, profesor de educación física y las posibilidades de acción en contra de la jornada escolar. Dos instituciones situadas en Curitiba, una pública y otra privada fueron encuestados. Desde un análisis cualitativo con las observaciones sistemáticas, registrado en un diario de campo y preparación de categorías analíticas. Llegamos a la conclusión de que la presencia de elementos educativos es posible dentro de las prácticas de ocio trabajado en contra, a su vez, se destaca entre ellas: la identificación de estudiantes y profesores, fomentando las discusiones con enfoque educativo y crítico, formas de presentación de los contenidos y relaciones con sus experiencias.

Palabras clave: Ocio, turno Contra, el profesor de Educación Física. 